\title{
Sprawl and mega-events: Economic growth and recent urban expansion in a city losing its competitive edge (Athens, Greece)
}

In the new context of contemporary cities, local competitiveness for financial resources has grown more than ever, resulting in cities characterised by important socioeconomic transformations. Earlier studies addressed the relation between urban expansion, socioeconomic development and mega-events only for specific areas and types of urban growth, often overlooking the role of mega-events in fuelling urban sprawl. As the host of the 2004 Olympic Games, Athens, Greece is a paradigmatic example for emerging cities hosting mega-events due to the close interconnection between the Olympics, infrastructure development and urban sprawl. This article connects the latent relationship between economic expansion driven by the Olympic Games and laissez-faire urbanism to the long-term unregulated urban expansion characterising Athens's development. By providing room for the original wave of sprawl, the resulting socioeconomic context is interpreted as a signal of the weakness of the "competitive city" framework in poorly planned and long-deregulated urban contexts such as Athens. A comprehensive analysis of recent phases of economic growth and discontinuous urban expansion thus provides further insight into understanding sprawl processes in today's cities, and helps distinguish the morphological patterns and socioeconomic dynamics that characterise urban expansion during sequential cycles of economic expansion and recession.

Keywords: urban expansion, economic growth, infrastructure, agglomeration economies, tourism, Mediterranean 


\section{Introduction}

Urban growth is a global phenomenon that is manifested through various spatial forms and dynamics (Angel et al., 2011). Socioeconomic restructuring processes and the resulting distribution of economic activities at the global scale suggest that the growth prospects of cities increasingly depend on their comparative advantages to attract investments and generate local development opportunities (Bennet \& Savani, 2003). Factors such as infrastructure and accessibility, industry and economic scale, human capital and labour force act as major determinants of urban competitiveness (Andersen et al., 2011). Policies to enhance the capacity of cities to attract businesses and labour have shaped regional and local policy in developed countries (OECD, 2006).

In this new global competitive context and in the era of mass communication, the importance of mega-events, including the Olympic Games, expos and football world cups, has significantly scaled up (Chorianopoulos et al., 2010). The potential of hosting major events today lies in the global attention that a country and a city receive throughout the period, serving advertisement and promotion purposes (Delladetsima, 2006). Mega-events thus serve as a means for attracting human and financial investments from all over the world. Competitiveness among cities hoping to host such events has increased greatly (Phelps et al., 2006). Cities have undergone radical changes, promoting intense infrastructure development, urban re-qualification plans and the "construction of territorial specificities" with the final objective of enhancing the growth potential of the locality (Scott, 2001). To sum up, cities have been transforming at greater speeds in order to become more competitive for hosting mega-events.

The shift toward a "competitive city" model is noticeable in two regulatory responses seeking to modify the competitive attributes of urban systems (Kresl, 2007). The first is demandoriented actions, striving to respond to the attributes that firms are seeking from a particular location in order to operate. A key example of such a response is the construction of physical infrastructure designed to make the area more attractive for investment and favourable for the establishment and growth of local economic initiatives. The second regulatory response is profile development or enhancement strategies, aiming to differentiate a place from other investment choices by highlighting its core benefits, style and culture. The promotion of rejuvenated urban profiles involves mobilising diverse policy tools and resources, including the preservation of architectural heritage sites, flagship property developments aimed at altering city-centre landscapes and hosting major cultural, entrepreneurial and sports events. In this respect, place marketing considerations are now viewed as a fundamental part of land-use planning, guiding the development of places (Bennet \& Savani, 2003).

In the new context of entrepreneurial cities, local competitiveness for financial resources has grown more than ever, resulting in competitive cities characterised by morphological and functional transformations (Di Feliciantonio \& Salvati, 2015). In this regard, mega-events are a strong means of selfpromotion, and for this reason they have always been preceded by infrastructure development and strategies to enhance the profile of the host city (Longhi \& Musolesi, 2007). However, the close relationship between mega-events, socioeconomic development and urban expansion was addressed only for specific areas and types of urban growth, often overlooking the role of mega-events in fuelling dispersed urbanisation and producing negative socio-environmental externalities (DuraGuimera, 2003). As the host of the 2004 Olympic Games, Athens is a paradigmatic example for Olympic cities due to the close interconnection between mega-events, infrastructure development and urban sprawl in a socioeconomic context characterised by long-term unregulated city expansion (Chorianopoulos et al., 2014).

Athens's bid for the Olympic Games was perceived as the will of the city to regain urban competitiveness (Gargiulo Morelli et al., 2014). When Greece was awarded the games, several urban and infrastructure projects were launched. These sought to reduce economic marginality and improve the functional profile of the metropolis (Gospodini, 2006). The games acted as a catalyst to redirect spatial policy towards improving Athens's urban landscape (Beriatos \& Gospodini, 2004). At the same time, the pre-crisis phase of urban expansion typical of Athens created an unsustainable path of local development possibly reducing (or even compromising) the capacity of the metropolitan system to effectively respond to the subsequent negative impacts of recession (Gospodini, 2009). Based on these premises, this article discusses the latent relationship between economic expansion driven by the Olympic Games and laissez-faire urbanism, identifying a massive process of sprawl, considered an early signal of the weakness of the competitive city framework in poorly planned and long-deregulated urban contexts (Salvati et al., 2016). A comprehensive analysis of recent phases of economic growth and discontinuous urban expansion provides further insight into the understanding of sprawl patterns and processes in today's cities, and helps identify the morphological transformations and socioeconomic dynamics that characterise urbanisation paths in mixed cycles of economic expansion and recession.

After a brief description of the long-term demographic and urban development of the Athens metropolitan region (Section 2), four homogeneous phases of urban expansion are described 


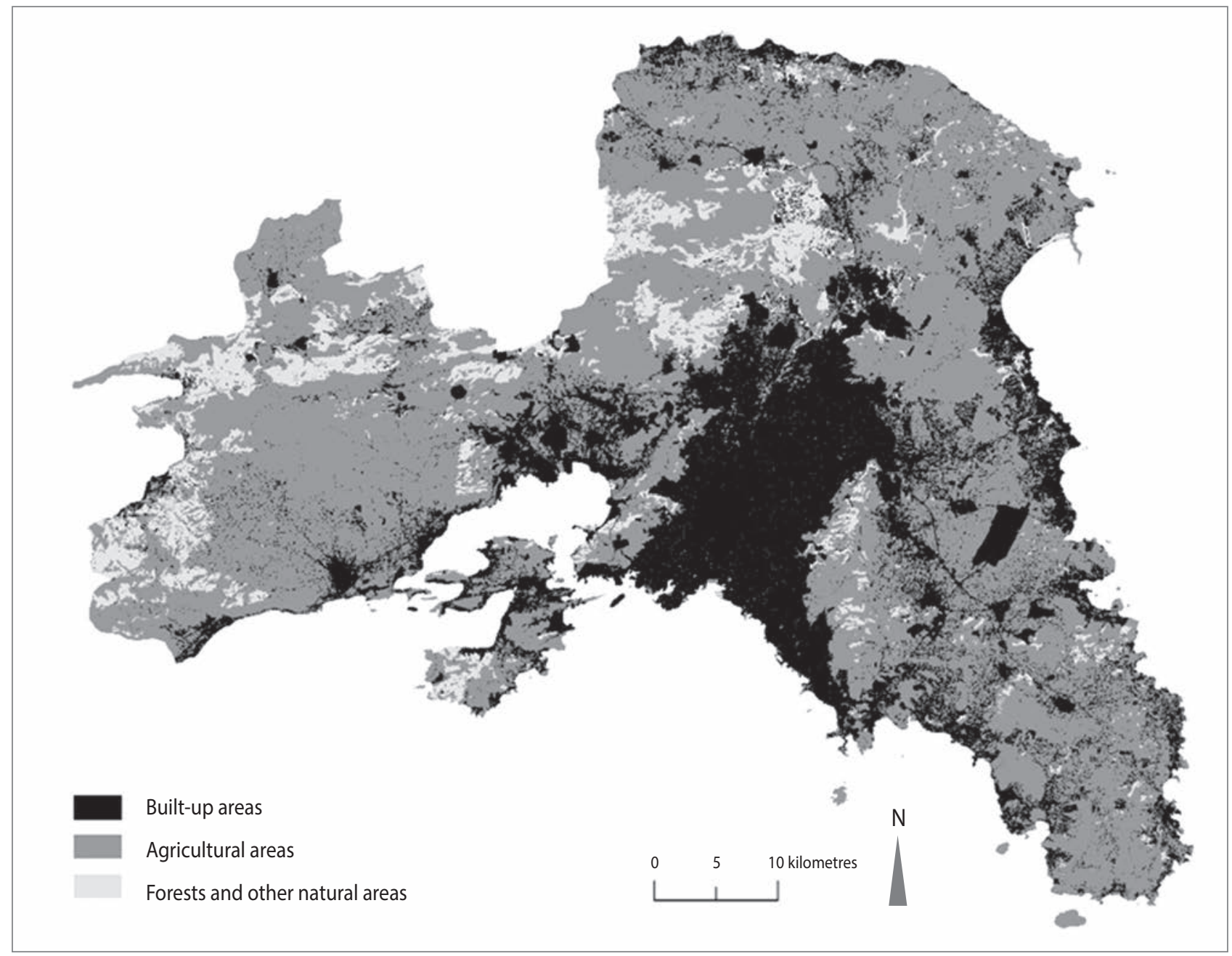

Figure 1: Spatial distribution of basic land-use classes in the Athens metropolitan region (source: European Environment Agency, 2012).

by reviewing empirical evidence presented in earlier studies. Section 3 then focuses on Athens's development in the last decade and the importance of the role played by the 2004 Olympics through a survey of recent literature on urban growth and sprawl in the Greek capital, coupled with additional analysis of material such as town plans, strategic guidelines for urban development and online newspaper articles. The implications of these global events in the new context of competitive cities is discussed in Section 4, presenting the urban transformations that cities are undergoing in order to increase their global competitiveness. The urban policies and strategies adopted by the Greek authorities before and immediately after the Olympics are briefly discussed in Section 5 . The spatial consequences of these urban development plans are addressed in Section 6. In particular, special attention is given to the transformation of the Mesogeia Plain, one of the main areas of the region affected by Athens's urban spillover, using statistical data provided by the Greek National Statistical Service and diachronic aerial photographs from Google Earth.

\section{Athens's expansion: a long urbanisation history}

The study area considered here is the administrative region of Attica in south-central Greece. Attica covers 3\% of Greece's area but contributes to almost half of its GDP (Figure 1). In 2001 the greater metropolitan area of Attica had a population of about 3.5 million, which is $34 \%$ of the total population (Salvati, 2016). In the Greek urban system, Athens is the capital and by far the most important city, with a concentration of all economic sectors and activities (especially high-level public administration, business headquarters and a wide array of services). However, Athens ranks low within the European urban system. According to various classifications of European cities, Athens is considered a peripheral city with a relatively low level of influence on both the Mediterranean region and, more generally, European dynamics (Rontos et al., 2016).

Kostas Rontos and Luca Salvati (2014) identified four growth phases in Athens. The first phase (1850-1900) was character- 
ised by a similar demographic expansion of urban and rural areas, resulting in quite a balanced distribution of population across regional territory. However, starting in the 1860s the growth rate of Athens began accelerating faster than the rest of Attica. The second phase (1900-1940) saw the development of a compact polycentric configuration, based on the two main urban centres of Athens and Piraeus (Leontidou, 1990).

Consolidating the role of Greek capital, greater Athens attracted industrialisation, especially in Piraeus, where the commercial port is located. Consequently, population growth rates in these two areas (mainly determined by immigration flows from Asia Minor) were very high. New residents settled in unplanned suburbs in the surroundings of Athens and Piraeus. Even if these informal settlements were not exactly low-density, the first signs of urban sprawl were evident in this period. The third phase (1950-1980) was characterised by the progressive transformation of the traditional di-centric structure of Attica. Workers and lower-income strata, together with rural immigrants, moved to the surroundings of Athens and Piraeus in search of affordable housing close to industries. Consequently, the difference between residential densities in the urban centres and peripheries decreased rapidly. Furthermore, the urbanisation of rural areas around Athens and Piraeus also took place in this phase, especially in the Mesogeia Plain. Urban depolarisation was mainly possible due to the infrastructure development of the region and the permissive urban policies and building code (Leontidou, 1996).

Dispersed urbanisation grew in the fourth phase (19801990), when the middle-class and elite urban exodus became significant. Athens's periphery, rural zones and coastal areas experienced rapid economic expansion during those years. The Athens urban area experienced growth and sprawl at the same time. The conclusion on the demographic and urban development of the region is that Greece's traditional city-countryside polarisation radically changed during the twentieth century. The compact polycentric configuration of Attica based on the Piraeus-Athens polarity is progressively being replaced by a more scattered metropolitan structure (Sayas, 2004, 2006; Polyzos et al., 2008; Salvati, 2013).

\section{Competing for mega-events: early signs of a competitive city in Athens}

With about one-third of Greece's population and over onethird of its total income, the Athens metropolitan region dominates the Greek urban system. However, for many decades Athens had one of the lowest indicators of competitiveness in Europe due to a variety of factors related to its introverted economic trends, persistent social problems and outdated infrastructure (Prevelakis, 2000). The Olympics were therefore perceived as an opportunity to project a new "winner" profile for the capital and, in the words of the organisers, to prove to the world that the city also has a future alongside a glorious past. In this light, staging the games was perceived as a national rather than local effort (Beriatos \& Gospodini, 2004). The central government reoriented regional policy towards this goal and allocated considerable funds to realise projects directly aimed at raising urban competitiveness (Chorianopoulos et al., 2010).

Two key project categories resulted from this prioritisation. The first is projects aimed at improving the attractiveness of the urban area and the city's capacity to act as an international venue for year-round tourism (examples include the unification of archaeological sites in the city's historical centre, the regeneration of the western waterfront area and the post-Olympic conversion of sporting facilities to convention, business and entertainment venues). The second category is projects to reduce economic marginality and improve the functional aspects of the metropolitan area, focusing on telecommunication and transport infrastructure (examples are the new Athens underground, with its new Lines 2 and 3 and improvement of Line 1 with an extra lane, the suburban railway and tramway connecting the city centre to the western waterfront, Eleftherios Venizelos International Airport and Athens's ring road).

The Olympic Games therefore acted as a catalyst for redirecting spatial policy toward the promotion of urban competitiveness (Gospodini, 2006). Leaving aside the discussion over the extent of economic growth of the city and country, we focus our attention on the effects that this spatial policy has had on the urban development of the area studied. Two major aspects played a crucial role in guiding urban development in the region: a) the emergence of new spatial links via development of major transport projects establishing new connections between peripheral areas, expanding the functional urban limits and transforming the geography of the metropolis, and b) changes in real estate dynamics, associated with a high level of infrastructure investment and major architectural works ( $\mathrm{Pa}$ nagiotis \& Tassos, 2004). The former aspect has contributed to an increase in the attractiveness of rural areas surrounding the central city (infrastructure development has mainly been channelled into the Mesogeia Plain and along the eastern and western coast), and the latter aspect has determined clusters of culture and leisure epicentres characterised by innovative design and distinct architectural and urban morphology with international rather than local references (Beriatos \& Gospodini, 2004). The emergence of developers' consortiums, focusing on investment opportunities in large retail, offices, entertainment and housing estate projects, has progressively affected land prices, intensifying development pressures (Delladetsima, 
2006). Infrastructure investment took place in various locations around Athens. However, it was primarily channelled into the eastern part of the metropolis: namely, the Mesogeia Plain (Couch et al., 2007).

\section{Infrastructure development and urban growth in Athens}

Lifestyle-related and infrastructure-driven sprawl are the two main factors underlying urban dispersion (Richardson \& Chang-Hee, 2004; Bruegmann, 2005; Salvati \& Carlucci, 2016). Studying infrastructure development in the case of Attica is convenient for understanding past patterns of urban expansion and predicting future ones. Among the most important infrastructure typologies that determine the nature and characteristics of sprawl processes, airports, roads and underground lines play a pivotal role (Zagorianakos, 2004). The development of the first "urban rapid transit system" (Line 1) in greater Athens connected central Piraeus to central Athens and was inaugurated in 1869. This was one of the first underground systems in the world. Later, in 1957, Line 1 underwent rapid development, and today it extends $20 \mathrm{~km}$ from the southwest corner of greater Athens (Piraeus) to the northeast areas (Kifissia).

In 1992, the Attiko Metro enterprise took over the management of the Athens metro system and began operations to build Lines 2 and 3 and upgrade Line 1. The total cost of these operations was approximately EUR 4.3 billion. Today, the Athens metro network extends more than $60 \mathrm{~km}$ and a new fourth line is under construction. The entire transit system in Athens was progressively transformed with the aim of serving as many areas of the Athens Basin as possible. Public transportation offers numerous benefits: speed, comfort, safety and reliability). The construction of Line 4 and the extensions planned for Lines 2 and 3 have greatly contributed to connecting peripheral areas in the northeast and south of greater Athens with the urban centre. However, an indirect result has been the consolidation of a discontinuous urban fabric, especially in the northeastern districts of greater Athens. Moreover, it is reasonable to predict that urban sprawl will inevitably increase in those areas due to the expected increase in the desirability of these areas because of infrastructure development.

Regarding the highway system, the A6 motorway (the Attiki Odos) is a modern motorway extending $65 \mathrm{~km}$. It constitutes the ring road of the greater metropolitan area of Athens and the core of the road network of the Attica region, connecting Eleftherios Venizelos International Airport in Spata to Corinth and Patras. The motorway was built with the main objectives of reducing traffic volume in the capital and the Athens Basin and contributing to physical planning and town planning development in the prefectures of Attica. With regard to the last two objectives, the A6 motorway plays a crucial role in shaping urban development in the peripheral areas of greater Athens and in the rest of Attica. The leapfrog and ribbon sprawl of the last decade can be considered largely due to highway development. Furthermore, the extension plan of the highway in the Mesogeia Plain (connecting the area to greater Athens through Mount Hymettus) is expected to contribute significantly to the diffused urbanisation of the plain (Chorianopoulos et al., 2014).

\section{The Olympics bid and Athens's chance at competitiveness: implications for urban sprawl}

Mega-events are clearly a great opportunity for regenerating the urban environment of a city. Nevertheless, if planning strategies are not correctly made, mega-events may impact negatively on the urban quality of the host city. In Athens, as in many other cities, the success of a strategic urban development plan may have been the root of problems arising from the revaluation of certain urban areas. According to FranciscoJavier Monclùs (2003), the quickening of decentralising tendencies and the exponential increase in metropolitan mobility correlates with considerable costs in energy, land use and commuting times. In contrast to the successful international experience of many cities in taking advantage of mega-events to regenerate large inner-city areas, Athens did not adopt such a strategy (Petsimeris, 2008). Although there were sites in former industrial inner areas (such as the Eleonas area in the Municipality of Athens), projects for the 2004 Olympics were not clustered there but instead distributed throughout Attica.

As a consequence, following Elias Beriatos and Aspasia Gospodini (2004), this pattern implies a strategy designed to promote multinucleated urban regeneration and development. Furthermore, several planned epicentres of culture and leisure constructed for the Olympic games, involving huge public funds, have failed to shape a new culture and leisure quarter in the city's landscape because they have been scattered throughout Attica (Figure 2). Most of the athletic complexes have been complemented by other amenities, such as convention and exhibition halls, commerce, entertainment, parks and promenades, with a view to improving the quality of urban space and the city's profile. In this respect, they constitute clusters of culture and leisure (Gospodini, 2001) dispersed throughout the metropolitan districts of Attica (inner-city areas, peripheral urban areas and the suburban fringe). 


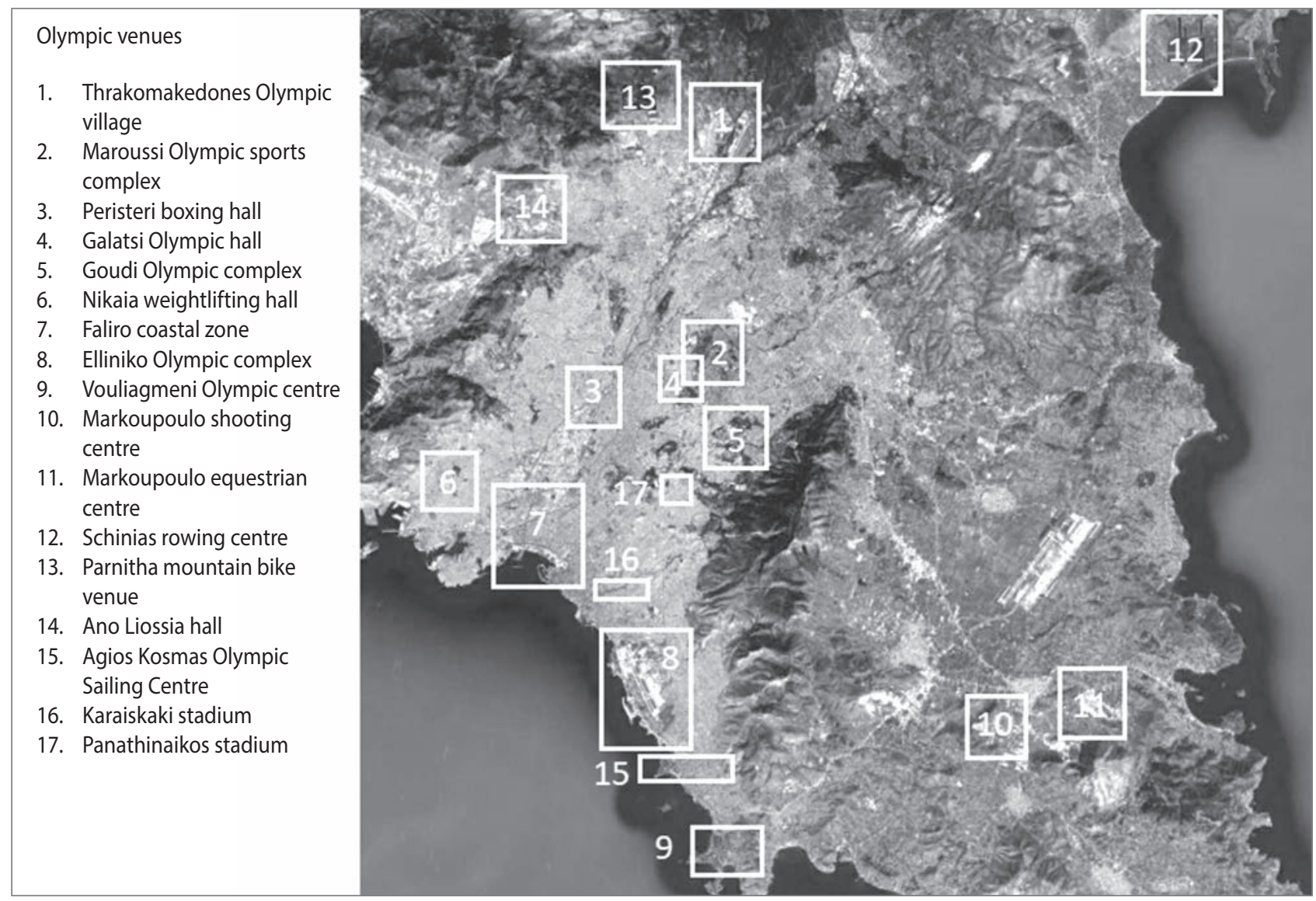

Figure 2: Olympic venues in greater Athens; venues no. 10 and 11 are located in the Mesogeia Plain (source: Google Earth, 2010).

Table 1: Land value percent change by area and reference period (source: Greek National Statistical Office, 2014).

\begin{tabular}{lllll}
\hline Area & \% change & \multicolumn{2}{l}{ Difference from Athens } \\
\hline & $1997-2000$ & $2004-2009$ & 2004 & 0.8 \\
\hline Total Greece & 51.9 & 17.7 & 0.7 & 0.9 \\
\hline Attica & 40.6 & 10.5 & 1.0 & 1.0 \\
\hline Prefecture of Athens & 122.7 & 7.8 & 1.0 & 0.9 \\
\hline Prefecture of East Attica & 23.5 & 20.9 & 0.8 & 0.6 \\
\hline Prefecture of West Attica & 8.3 & 5.5 & 0.6 & 0.8 \\
\hline Prefecture of Piraeus & 8.1 & 12.6 & 0.8 & \\
\hline
\end{tabular}

Table 1 shows the percent change of land values over two reference periods (1997-2000 and 2004-2009) in Greece, in Attica and in its four prefectures (Athens, Piraeus, West Attica and East Attica). Land values evidently increased in all zones investigated in both reference periods. However, the observed increase was greatest in the period 1997-2000 for all zones except the Prefecture of Piraeus, probably the most compact in the study area. Furthermore, it should be emphasized that in both periods the increase in land value in the Prefecture of East Attica (the Mesogeia district), where urbanisation has mostly concentrated in the last decades, has been particularly consistent. The most interesting results are obtained by observing the evolution of land values as an absolute deviation from what was observed for the Prefecture of Athens, which has always been the most expensive area of the country. These differences significantly increased for all of the areas investigated between 2004 and 2009, except for the Prefecture of West Attica, which has practically remained constant throughout the period. This observation may lead to the conclusion that land values across Attica are becoming more homogeneous with time. Demand for areas outside the Prefecture of Athens gradually grew as urbanisation and infrastructure development proceeded in Attica (Panagiotis \& Tassos, 2004).

Leapfrog and ribbon sprawl have been significantly encouraged by the dispersal of Olympic venues across the region thanks to the development of the transport sector, above all in the Mesogeia Plain. These typologies of sprawl, indirectly 

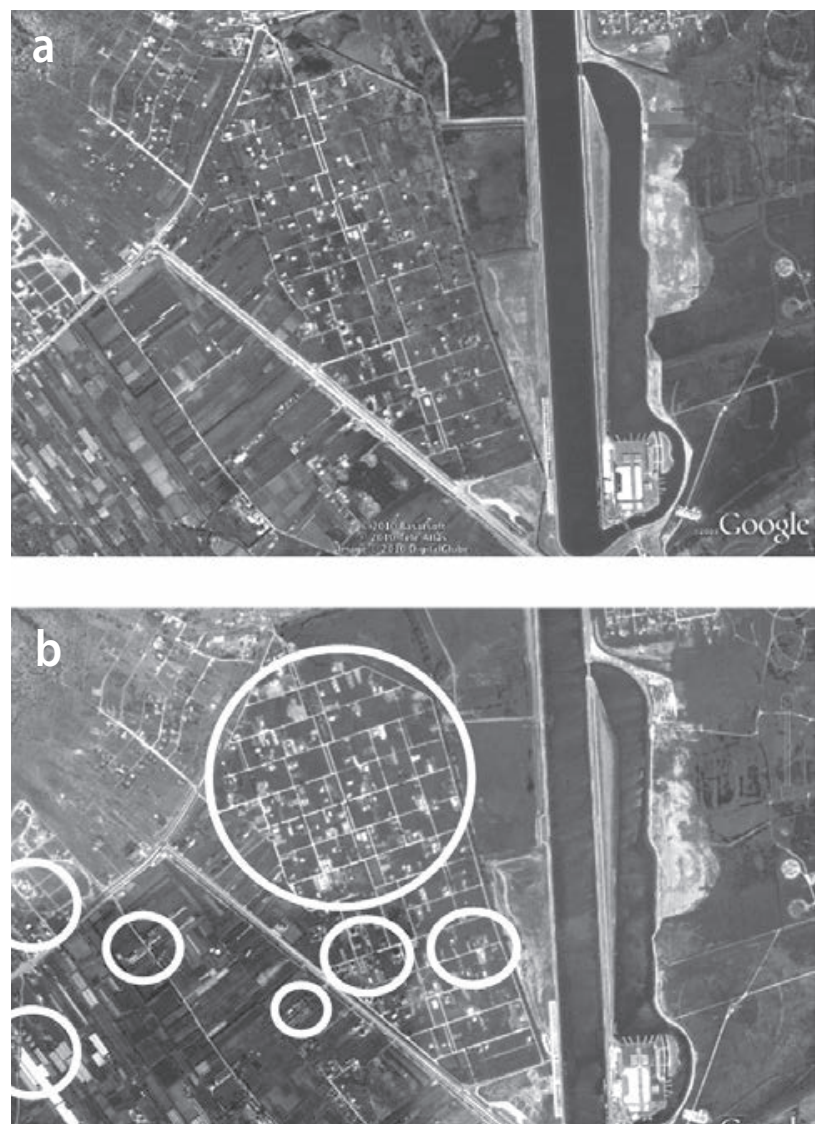

Figure 3: Urban development next to the Olympic Schinias rowing centre: a) in April 2004 and b) in June 2010; leapfrog development is characterised by isolated settlements and small urban nuclei expanding in rural environments. Ribbon sprawl is a typical expansion mode along roads and other infrastructure networks (source: Google Earth, 2012).

driven by sports installations, gave Attica a multi-nucleated spatial configuration, with the formation of clusters around districts that followed a laissez-faire spatial development program in contrast to the expectation of Athens's strategic master plan (Figure 3). The formation of a multi-nucleated territorial asset is particularly evident in the case of the Mesogeia Plain, a vast area that extends east of the Athens conurbation. Mount Hymettus to the west of the area acts as a physical barrier separating the plain from the main conurbation. The beginning of the transformation of the Mesogeia Plain started in the 1980s, when the decision was made to relocate the city's international airport to the area. Subsequent appropriation of agricultural land for airport construction was followed by further infrastructure investment, which was made possible by funds for the Olympic Games. The construction of new roads and rail links connecting the airport with the city significantly improved the areas accessibility. The picture was completed with the construction of two major Olympic venues (the Equestrian Centre and the Shooting Centre, both near the town of Markopoulo), again built on appropriated agricultural land.
Urban expansion in the Mesogeia Plain has been unplanned and greatly influenced by the infrastructure development of the area. The concentration of industrial activities, major investments in transport infrastructure for connecting the area to the rest of Attica and the relatively low costs of land have made the Mesogeia Plain extremely convenient for building activities and suburban growth (Chorianopoulos et al., 2014). As a result, the area's population grew by 26,207 during the 1980 s and 38,737 in the 1990s. The number of households in the Mesogeia Plain increased from 15,800 in 1981 to 37,117 in $2001(+135 \%)$, whereas the average household size fell from 3.3 to only 1.3 residents in 2001. In the same period, the population of greater Athens was decreasing in contrast to the inverse trend in its surroundings (Couch et al., 2007).

To identify the socioeconomic consequences deriving from such infrastructure investment activity, a comprehensive spatial planning study of the Mesogeia Plain was commissioned in the early 1990s. The study led to the creation of new land-use regulations for the area, including subdivision and building restrictions that were activated as late as 2003 , a year before the games commenced and almost two decades after the adoption of the Athens Strategic Master Plan (Giannakourou, 2005). At that time, the extent of new urban land use that corresponded to large-scale infrastructure projects amounted to $15 \%$ of total land use in the Mesogeia Plain. More than 50\% of new urban land use materialised in areas designated as protected (green zones or agricultural land). Such zones consumed up to $10 \%$ of the Mesogeia Plain and exhibited the highest rate of increase in urban land use. Moreover, built-up land expanded in both old and newly designated industrial zones, suggesting a trend towards the location of productive activities in the area. Less than $15 \%$ of new urban land use took place in areas regulated by structural urban plans. This category also showed the lowest rate of increase in urban land use among all Mesogeia Plain planning zones (Chorianopoulos et al., 2010).

\section{Outcomes of a competitive city: The Olympic sprawl wave in Athens}

Athens is a typical example of the Mediterranean city archetype, with urban development having long been mostly unplanned and spontaneous (Carlucci et al., 2017). Because it is representative of southern European urban areas still presenting a moderate demographic increase and over-urbanisation, Athens's expansion exemplifies the complex relationship between mega-events and sprawl (Ioannidis et al., 2009). Based on extensive knowledge about pre-Olympic sprawl processes in the area (Leontidou, 1996; Maloutas, 2007; Arapoglou \& Sayas, 2009; Chorianopoulos et al., 2014), a review of the various modalities and dynamics of sprawl in the case of 
Attica is presented here, identifying four processes typical of the Olympic phase of urban expansion based on distinct socioeconomic dynamics at the local scale: a) leapfrogging expansion, b) metropolitan periphery industrial development, c) ribbon development and d) second home conversion into primary residences.

There are many cases of urban sprawl leapfrogging to places outside the conurbation but still remaining within commuting distance. Examples of sprawl attached to existing villages away from the city, around "green villages," along seashore towns or related to "action planning legislation" can be seen throughout Attica. Leapfrogging urban sprawl was usually associated with the construction of mega-structures or industrial sites. For this reason, the 2004 Olympic Games, with all the work carried out for such a mega-event, greatly intensified this typology of sprawl. For example, the construction of the Olympic Village was another case of leapfrogging over still-undeveloped land, and it is becoming a remote but upscale housing complex for workers. For various reasons, sprawl by other population groups has emerged next to major Olympic infrastructures and in other parts of Athens's periphery (Emmanuel, 2004).

Regarding regional industrial development, factories first appeared in Athens's periphery on the borders between northern Attica and Boeotia. This suburban manufacturing growth initially took place spontaneously in clusters near major transport arteries (Kourliouros, 1997). Sprawl followed this process with the migration of workers to peri-urban industrial spaces in the Mesogeia Plain and outside Attica (along the national highway from Athens to Lamia in the north and along the highway from Athens to Corinth in the southwest). Hybrid landscapes were the result of the coexistence of rural/urban and residential/industrial/commercial land use. It may be argued that this typology of sprawl is morphologically similar to ribbon development sprawl. Nonetheless, it has been separated from the latter because it has different causes.

Concerning ribbon development and post-suburbia, in the first post-war decades agricultural land urbanisation was controlled by building regulations adopted by city plans. These plans allowed the development of several urban uses (housing, industrial and commercial) along transport axes, determining a narrow strip form of sprawl (Economou, 1997). This is a type of infrastructure-driven sprawl in which transport routes play a dominant role. Increasing car ownership meant that houses would be sellable even though they might be remote from shops and other services. The actors that initiated it were various decentralising land-intensive and transport-dependent urban activities such as branch plants, warehouses, commercial exhibition centres and superstores. Zoning arrangements or other forms of regulations for land-use control did not exist in such ribbon development, thus producing clusters or districts of similar activities highly dependent on transport systems (Coccossis et al., 2005). This typology of urban development led to progressive abandonment of the compact city tradition typical of the Mediterranean region (Economidou, 1993).

A special case of ribbon development occurred when the east and west coasts of Attica were connected with the inner city. Many middle-class residents of the city owned second homes on the periphery of the city close to the coast so that they could spend free time in quiet areas near the sea (Sayas, 2006). As transport infrastructure developed, these areas became more accessible from the city centre, making commuting possible (Couch et al., 2007). Thus, peripheral centres turned from summer locations into primary residences for middleand upper-class groups. As European integration proceeded, and especially after the Maastricht Treaty, affluent populations migrated beyond cities and national borders for seasonal periods. This seasonal migration phenomenon was also significantly scaled up with the arrival of low-cost airlines, which made travel affordable for larger groups of individuals.

As a consequence, the Mediterranean coasts experienced a wave of residential tourism from north-south migrants, creating a sort of long-distance sprawl. Greece, together with Spain and Italy, is a favourite Mediterranean destination for seasonal migrants. The Athens 2004 Olympic Games greatly stimulated tourism to the country, and German, British and Austrian citizens purchased houses along the coasts of Attica. Nearly 30\% of new housing in this area has been acquired by foreigners, and international investors predict that there will be demand for one million houses for tourists in the near future (Couch et al., 2007).

\section{Discussion}

To understand the socioeconomic dynamics and morphological characteristics of the most recent sprawl wave of Mediterranean urbanisation, this study focused on the urban spillover typical of Olympic Athens, with the 2004 games having played a crucial role in shaping the sprawl dynamics of the region. The interest in providing a detailed analysis of Athens's recent development - as a representative example of Mediterranean cities attracting more population than jobs - derives from various reasons (Allen et al., 2004). Athens's urban expansion has been widely recognised as a typical example of the recent socioeconomic trajectories followed by southern European cities, which are now experiencing a transformation from compact development to sprawl and, possibly, polycentric expansion (Turok \& Mychnenko, 2007). Until the 1990s Athens was considered a compact city, but today the city is attracting 
the attention of scholars for its progressive deviation towards sprawling patterns of urbanisation. Understanding the reasons and causes behind this transition from compact development to the current spillover process is important for better understanding future urban patterns in the Mediterranean region and, possibly, all over Europe.

A further characteristic of the Mediterranean city that is particularly evident in Athens is the unplanned mode of its expansion (Vaiou, 1997). In most Mediterranean cities urbanisation has not been preceded by legislation for spatial allocation, land use and settlement, as in the rest of Europe. Furthermore, Athens is one of the few large European urban areas manifesting, at least up to the late 2000s, an intense demographic increase, followed by a drastic over-urbanisation process that has transformed the typical rural landscape surrounding the central city (Weber et al., 2005). For these reasons, now more than ever, the area requires a detailed spatial analysis in order to use appropriate policy strategies to control a process of dispersed urban expansion that is particularly recent and intense (Kasanko et al., 2006; Schneider \& Woodcock, 2008; Salvati, 2014).

Finally, Athens is a good example for discussing the importance of mega-events in the new context of city regions. In addition to placing Greece in the world's eyes, the Olympic Games made the city an example for studying how new competitive city dynamics influence urbanisation processes (Gospodini, 2009). The works carried out for mega-events in Attica have had two main consequences: the emergence of new spatial links (including the expansion of the functional urban limits) and changes in real estate dynamics (raising values of rural and peripheral land). Furthermore, these interventions have been distributed throughout the Athens urban area, determining a sort of multi-nucleated urban regeneration programme (Gospodini, 2006). Consequently, ribbon and leapfrog sprawl patterns have been encouraged, thus contributing to the spillover process of Athens. Urban sprawl has been most evident in the Mesogeia Plain, an area traditionally dedicated to agricultural activities. The overall result is an increase in urban land use around industrial sites and Olympic venues (e.g., the shooting and equestrian centre), in designated protected areas and along major transport infrastructure. Furthermore, an intense demographic increase has been registered in the area, together with a decrease in the average household size.

Leapfrogging sprawl spatial patterns have mainly been observed in Attica. Many of these small sub-centres separated from the city (although connected by roads and railways) have developed around Olympic venues. Other "sub-types" of leapfrog development have been observed, such as new settlements created by interest groups and urban clusters around industrial sites. Ribbon development is another common sprawl pattern that has been noticed throughout the region. Strip developments have sprung up along major transport axes, such as the A6 motorway. This suggests that infrastructure-driven sprawl is a dominant form of recent urban expansion in Athens. This pattern has been significantly influenced by the decentralisation of land-intensive and transport-dependent activities, including industries and commercial centres. A sub-type of ribbon sprawl that has also been observed is the conversion of second homes to primary residences. As the connection between coastal areas and the city improved, many middleclass residents of the metropolis with seasonal vacation houses decided to convert them into their primary residences. Consequently, former vacation localities have undergone radical socioeconomic transformation towards urban use.

There is general agreement on the fact that the modalities with which Athens's urban development occurred throughout the twentieth century reflect both direct causes and indirect factors, as already observed elsewhere (e.g., Arbaci, 2008; Catalàn et al., 2008; Terzi \& Bolen, 2009; Bayona-Carrasco \& GilAlonso, 2012; Litynski, 2016; Salvati \& Carlucci, 2016). As a consequence of the morphological characteristics of Greek territory, the urban system of the country has been characterised by a persistent urban-rural polarisation (Costa et al., 1991). Nevertheless, the traditional relationship between urban and rural areas in Greece rapidly transformed throughout the twentieth century. This transformation, stimulated by the capital's economic development, its peculiar dimensions, significant waves of immigration, a weak planning system combined with a "permissive" building code and the infrastructure development of the region, has modified the spatial assets of the Attica region, resulting in a progressive (and discontinuous) urbanisation of the surrounding areas of greater Athens (Di Feliciantonio \& Salvati, 2015). Consequently, this is contributing to the gradual decline of the urban-rural polarity, typical of the Mediterranean tradition. Showing similar traits as Spanish, Portuguese and Italian cities, its economic structures in the post-war period of rapid urbanisation were based on urbanisation economies triggering sparse industrialisation (Carlucci et al., 2017). As a result, the city did not experience the usual deindustrialisation/dis-urbanisation wave often noted in northern European cities since the 1970s. It has continued to show population gains, displaying a distinct lifecycle model (Gargiulo Morelli et al., 2014).

At the same time, in most Mediterranean cities urbanisation has not been preceded by legislation for spatial allocation, land use and urban settlement, as in the rest of Europe (Coccossis et al., 2005). Urban development has mainly occurred through 
illegal self-built housing sprawling onto cheap suburban land with severe infrastructure deficiencies (Economou, 1997). This has led to the social exclusion and vulnerability of the residents of such areas (Emmanuel, 2004). In this line of thinking, the recent growth trajectory in Athens supports the argument of "individualised urban development" because it portrays a city that continues to grow in an unplanned manner, based on small, self-financed property development schemes, with limited public expenditure for urban infrastructure mainly based on sporadic (albeit important) events (Couch et al., 2007).

\section{Conclusion}

The socioeconomic context characterising the latent relationship between economic growth stimulated by the 2004 Olympics and a laissez-faire urbanism wave contributing to Athens's sprawled expansion may be interpreted as a signal of the weakness of the competitive city framework in poorly planned and long-deregulated urban contexts. A comprehensive analysis of recent phases of economic growth and discontinuous urban expansion provides further insight into understanding the complex mechanisms of dispersed urbanisation in the contemporary metropolitan region. In this way, the new transforming territorial organisation of Attica stimulates re-thinking of the roles played by metropolitan areas. Attica is located at the centre of communication routes between the northern typically industrial part of the country, the western and southern areas characterised by a strong agricultural activities and the tourism-oriented Aegean islands. Should Attica instead of Athens be considered the new capital of Greece? Is this a simple process of urban spillover that occupies residual free space with respect for geographical constraints, or is it the effect of an urban relocation process that connects the entire region in a complex network, irrespective of metropolitan hierarchies, spatial contiguity, functional productive sites and different allocations of land? In this sense, the rules of a complex Mediterranean region in transition will be dictated by the new Attica region and no longer by Athens alone, suggesting that policies governing the metropolitan area will play a relevant role. Contrary to what was achieved for the Olympic installations, regional planning should abandon the orientation toward specific actions in sparse areas - sometimes dictated by emergency conditions - to regain a visionary programme for the Athens region that could be a model strategy for the future development of several Mediterranean cities between economic growth and urban decline.

\section{Luca Salvati}

Council for Agricultural Research and Economics (CREA), Arezzo, Italy E-mail: luca.salvati@crea.gov.it
Marco Zitti

Sapienza University of Rome, Rome, Italy

E-mail:marcozitti@libero.it

\section{References}

Allen, J., Barlow, J., Leal, J., Maloutas, T. \& Padovani, L. (2004) Housing in southern Europe. London, Blackwell. DOI: 10.1002/9780470757536

Andersen, H. T., Møller-Jensen, L. \& Engelstoft, S. (2011) The end of urbanization? Towards a new urban concept or rethinking urbanization. European Planning Studies, 19(4), pp. 595-611. DOI: $10.1080 / 09654313.2011 .548472$

Angel, S., Parent, J., Civco, D. L., Blei, A. \& Potere, D. (2011) The dimensions of global urban expansion: Estimates and projections for all countries, 2000-2050. Progress in Planning, 75(2), pp. 53-107. DOI: 10.1016/j.progress.2011.04.001

Arapoglou, V. P. \& Sayas, J. (2009) New facets of urban segregation in southern Europe. European Urban and Regional Studies, 16(4), pp. 345362. DOI: $10.1177 / 0969776409340187$

Arbaci, S. (2008) (Re)viewing ethnic residential segregation in southern European cities: Housing and urban regimes as mechanisms of marginalisation. Housing Studies, 23(4), pp. 589-613. DOI: 10.1080/02673030802117050

Bayona-Carrasco, J. \& Gil-Alonso, F. (2012) Suburbanisation and international immigration: The case of the Barcelona Metropolitan Region (1998-2009). Tijdschrift voor Economische en Sociale Geographie, 103(3), pp. 312-329. DOI: 10.1111/j.1467-9663.2011.00687.x

Bennett, R. \& Savani, S. (2003) The rebranding of city places: An international comparative investigation. International Public Management Review, 4(2), pp. 70-87.

Beriatos, E. \& Gospodini, A. (2004) Glocalising urban landscapes: Athens and the 2004 Olympics. Cities, 21(3), pp. 187-202. DOI: 10.1016/j.cities.2004.03.004

Bruegmann, R. (2005) Sprawl: A compact history. Chicago, University of Chicago Press. DOI: 10.7208/chicago/9780226076973.001.0001

Carlucci, M., Grigoriadis, E., Rontos, K. \& Salvati, L. (2017) Revisiting a hegemonic concept: Long-term "Mediterranean urbanization" in between city re-polarization and metropolitan decline. Applied Spatial Analysis and Policy, 10(3), pp. 347-362. DOI: 10.1007/s12061-016-9186-2

Catalàn, B., Sauri, D. \& Serra, P. (2008) Urban sprawl in the Mediterranean? Patterns of growth and change in the Barcelona metropolitan region 1993-2000. Landscape and Urban Planning, 85(3-4), pp. 174-184.

Chorianopoulos, I., Pagonis, T., Koukoulas, S. \& Drymoniti, S. (2010) Planning, competitiveness and sprawl in the Mediterranean city: The case of Athens. Cities, 27(4), pp. 249-259.

DOI: 10.1016/j.cities.2009.12.011

Chorianopoulos, I., Tsilimigkas, G., Koukoulas, S. \& Balatsos, T. (2014) The shift to competitiveness and a new phase of sprawl in the Mediterranean city: Enterprises guiding growth in Messoghia - Athens. Cities, 39, pp. 133-143. DOI: 10.1016/j.cities.2014.03.005

Coccossis, H., Economou, D. \& Petrakos, G. (2005) The ESDP relevance to a distant partner: Greece. European Planning Studies, 13(2), pp. 253264. DOI: $10.1080 / 0965431042000321811$

Costa, F. J., Noble, A. G. \& Pendeleton, G. (1991) Evolving planning systems in Madrid, Rome, and Athens. Geojournal, 24(3), pp. 293-303. DOI: 10.1007/BF00189030 
Couch, C., Petschel-Held, G. \& Leontidou, L. (2007) Urban sprawl in Europe: Landscapes, land-use change and policy. Oxford, Blackwell. DOI: 10.1002/9780470692066

Delladetsima, P. (2006) The emerging property development pattern in Greece and its impact on spatial development. European Urban and Regional Studies, 13(3), pp. 245-278. DOI: 10.1177/0969776406065428

Di Feliciantonio, C. \& Salvati, L. (2015) "Southern" alternatives of urban diffusion: Investigating settlement characteristics and socioeconomic patterns in three Mediterranean regions. Tijdschrift voor Economische en Sociale Geografie, 106(4), pp. 453-470. DOI: 10.1111/tesg.12102

Dura-Guimera, A. (2003) Population deconcentration and social restructuring in Barcelona, a European Mediterranean city. Cities, 20(6), pp. 387-394. DOI: 10.1016/j.cities.2003.08.004

Economidou, E. (1993) The Attic landscape throughout the centuries and its human degradation. Landscape and Urban Planning, 24(1), pp. 33-37. DOI: 10.1016/0169-2046(93)90079-S

Economou, D. (1997) The planning system and rural land use control in Greece: A European perspective. European Planning Studies, 5(4), pp. 461-476. DOI: 10.1080/09654319708720412

Emmanuel, D. (2004) Socio-economics inequalities and housing in Athens: Impacts of the monetary revolution of the 1990s. The Greek Review of Social Research, 113(A), pp. 121-143. DOI: 10.12681/grsr.9355

European Environment Agency (2012) CORINE Land Cover geospatial database. Available at: http://land.copernicus.eu/pan-european/corineland-cover/view (accessed 11 May 2017).

Gargiulo Morelli, V., Rontos, K. \& Salvati, L. (2014) Between suburbanisation and re-urbanisation? Revisiting the urban life cycle in a Mediterranean compact city. Urban Research and Practice, 7(1), pp. 74-88. DOI: 10.1080/17535069.2014.885744

Giannakourou, G. (2005) Transforming spatial planning policy in Mediterranean countries. Europeanization and domestic change. European Planning Studies, 13(2), pp. 253-264.

DOI: 10.1080/0365431042000321857

Google Earth (2010) Pro images collection. Available at: https://www. google.it/int//it/earth/ (accessed 11 May 2017).

Google Earth (2012) Pro images collection. Available at: https://www. google.it/intl/it/earth/ (accessed 11 May 2017).

Gospodini, A. (2001) Urban waterfront redevelopment in Greek cities. Cities, 18(5), pp. 285-295. DOI: 10.1016/S0264-2751(01)00022-1

Gospodini, A. (2006) Portraying, classifying and understanding the emerging landscapes in the post-industrial city. Cities, 23(5), pp. 311330. DOI: 10.1016/j.cities.2006.06.002

Gospodini, A. (2009) Post-industrial trajectories of Mediterranean European cities: The case of post-Olympics Athens. Urban Studies, 46(5-6), pp. 1157-1186. DOI: $10.1177 / 0042098009103859$

Greek National Statistical Office (2014) Population and housing cenzus. Available at: http://www.statistics.gr (accessed 11 May 2017).

loannidis, C., Psaltis, C. \& Potsiou, C. (2009) Towards a strategy for control of suburban informal buildings through automatic change detection. Computers, Environment and Urban Systems, 33(1), pp. 64-74. DOI: 10.1016/j.compenvurbsys.2008.09.010

Kasanko, M., Barredo, J. I., Lavalle, C., McCormick, N., Demicheli, L., Sagris, V., et al. (2006) Are European cities becoming dispersed? A comparative analysis of fifteen European urban areas. Landscape and Urban Planning, 77(1-2), pp. 111-130. DOI: 10.1016/j.landurbplan.2005.02.003

Kourliouros, E. (1997) Planning industrial location in Greater Athens: The interaction between deindustrialization and anti-industrialism during the 1980s. European Planning Studies, 5(4), pp. 435-460. DOI: $10.1080 / 09654319708720411$

Kresl, P. K. (2007) Planning cities for the future. The successes and failures of urban economic strategies in Europe. Cheltenham, UK, Edward Elgar. DOI: $10.4337 / 9781847204332$

Leontidou, L. (1990) The Mediterranean city in transition. Cambridge, Cambridge University Press. DOI: 10.1017/CBO9780511522208

Leontidou, L. (1996) Alternatives to modernism in (southern) urban theory: Exploring in-between spaces. International Journal of Urban and Regional Research, 20(2), pp. 180-197.

DOI: 10.1111/j.1468-2427.1996.tb00310.x

Litynski, P. (2016) The correlation between urban sprawl and the local economy in Poland. Urbani izziv, 27(2), pp. 86-96.

Longhi, C. \& Musolesi, A. (2007) European cities in the process of economic integration: Towards structural convergence. Annals of Regional Science, 41(2), pp. 333-351. DOI: 10.1007/s00168-006-0104-4

Maloutas, T. (2007) Segregation, social polarization and immigration in Athens during the 1990s: Theoretical expectations and contextual difference. International Journal of Urban and Regional Research, 31(4), pp. 733-758. DOI: 10.1111/j.1468-2427.2007.00760.x

Monclùs, F. J. (2003) El "Modelo Barcelona” ¿Una fórmula original? De la "reconstrucción" a los proyectos urbanos estratégicos. Urban Perspectives, 3, pp. 1-13.

OECD (Organisation for Economic Co-operation and Development) (2006) Competitive cities in the global economy. Paris.

Panagiotis, Z. \& Tassos, L. (2004) The impact of the Athens 2004 Olympic games on real estate value in Greece. Journal of Property Tax Assessment and Administration, 1(3), pp. 5-20.

Petsimeris, P. (2008) Playing with scales: Doxiadis legacy in urban theory and practice. Ekistics, 442, pp. 326-352.

Phelps, N. A., Parsons, N., Ballas, D. \& Dowling, A. (2006) Post-suburban Europe: Planning and politics at the margins of Europe's capital cities. Basingstoke, UK, Palgrave Macmillan. DOI: 10.1057/9780230625389

Polyzos, S., Christopoulou, O., Minetos, D. \& Leal Filho, W. (2008) An overview of urban-rural land use interactions in Greece. International Journal of Agricultural Resources, Governance and Ecology, 7(3), pp. 276296. DOI: 10.1504/IJARGE.2008.018330

Prevelakis, G. (2000) Athenes. Urbanism, culture et politique. Paris, L'Harmattan.

Richardson, H. W. \& Chang-Hee, C. B. (2004) Urban sprawl in Western Europe and the United States. London, Ashgate.

Rontos, K., Grigoriadis, S., Sateriano, A., Syrmali, M., Vavouras, I. \& Salvati, L. (2016) Lost in protest, found in segregation: Divided cities in the light of the 2015 "Oki" referendum in Greece. City, Culture and Society, 7(3), pp. 139-148. DOI: 10.1016/j.ccs.2016.05.006

Rontos, K. \& Salvati, L. (2014) Is the ratio of present to resident population a proxy for urban diffusion? A case study. International Journal of Ecological and Economic Statistics, 32(1), pp. 75-82.

Salvati, L. (2013) Exploring the spatial pattern of soil sealing in a Mediterranean peri-urban area. Journal of Environmental Planning and Management, 57(6), pp. 848-861. DOI: 10.1080/09640568.2013.770730

Salvati, L. (2014) Towards a polycentric region? The socioeconomic trajectory of Rome, an "ethernal" Mediterranean city. Tijdschrift voor Economische en Sociale Geografie, 105(3), pp. 268-284. DOI: 10.1111/tesg.12054 
Salvati, L. (2016) The dark side of the crisis: Disparities in per-capita income (2000-2012) and the urban-rural gradient in Greece. Tijdschrift voor Economische en Sociale Geografie, 107(5), pp. 628-641. DOI: $10.1111 /$ tesg. 12203

Salvati, L. \& Carlucci, M. (2016) Patterns of sprawl: The socioeconomic and territorial profile of dispersed urban areas in Italy. Regional Studies, 50(8), pp. 1346-1359. DOI: 10.1080/00343404.2015.1009435

Salvati, L., Sateriano, A. \& Grigoriadis, S. (2016) Crisis and the city: Profiling urban growth under economic expansion and stagnation. Letters in Spatial and Resource Science, 9(3), pp. 329-342.

DOI: 10.1007/s12076-015-0160-4

Sayas, J. P. (2004) An exploration of the social and spatial division of labour in the Athenian urban space. The Greek Review of Social Research, 113, pp. 167-206. DOI: 10.12681/grsr.9357

Sayas, J. P. (2006) Urban sprawl in the periurban coastal zones of Athens. The Greek Review of Social Research, 120(B), pp. 71-104.

Schneider, A. \& Woodcock, C. E. (2008) Compact, dispersed, fragmented, extensive? A comparison of urban growth in 25 global cities using remotely sensed data, pattern metrics and census information. Urban Studies, 45(3), pp. 659-692. DOI: 10.1177/0042098007087340

Scott, A. J. (2001) Global city-regions. Trends, theory, policy. Oxford, Oxford University Press.

Terzi, F. \& Bolen, F. (2009) Urban sprawl measurement of Istanbul. European Planning Studies, 17(10), pp. 1559-1570. DOI: 10.1080/09654310903141797

Turok, I. \& Mykhnenko, V. (2007) The trajectories of European cities, 1960-2005. Cities, 24(3), pp. 165-182. DOI: 10.1016/j.cities.2007.01.007

Vaiou, D. (1997) Facets of spatial development and planning in Greece. European Planning Studies, 5(4), pp. 431-433. DOI: 10.1080/09654319708720410

Weber, C., Petropoulou, C. \& Hirsch, J. (2005) Urban development in the Athens metropolitan area using remote sensing data with supervised analysis and GIS. International Journal of Remote Sensing, 26(4), pp. 785796. DOI: 10.1080/01431160512331316856

Zagorianakos, E. (2004) Athens 2004 Olympic Games' transportation plan: A missed opportunity for strategic environmental assessment (SEA) integration. Journal of Transport Geography, 12(2), pp. 115125. DOI: 10.1016/j.jtrangeo.2003.12.001 